\title{
Observations of Unexpected Short-Term Heating in the Uppermost Layer of the Dead Sea after a Sharp Decrease in Solar Radiation
}

\author{
Pavel Kishcha, ${ }^{1}$ Boris Starobinets, ${ }^{1}$ Isaac Gertman, ${ }^{2}$ Tal Ozer, ${ }^{2}$ and Pinhas Alpert ${ }^{1}$ \\ ${ }^{1}$ School of Geosciences, Tel Aviv University, Tel Aviv, Israel \\ ${ }^{2}$ Israel Oceanographic and Limnological Research, National Institute of Oceanography, Haifa, Israel
}

Correspondence should be addressed to Pavel Kishcha; pavel@cyclone.tau.ac.il

Received 18 November 2016; Accepted 18 April 2017; Published 25 May 2017

Academic Editor: Stefano Vignudelli

Copyright (C) 2017 Pavel Kishcha et al. This is an open access article distributed under the Creative Commons Attribution License, which permits unrestricted use, distribution, and reproduction in any medium, provided the original work is properly cited.

\begin{abstract}
The Dead Sea is one of the saltiest bodies of water in the world. Observational evidence has been obtained of unexpected short-term water heating in the $2 \mathrm{~m}$ uppermost layer of this hypersaline lake, following a sharp drop in solar radiation under weak winds. This was carried out using Dead Sea buoy measurements. Passing frontal cloudiness mixed with significant dust pollution over the Judean Mountains and the Dead Sea, which occurred on March 22, 2013, led to a dramatic drop in noon solar radiation from $860 \mathrm{~W} \mathrm{~m}^{-2}$ to $50 \mathrm{~W} \mathrm{~m}^{-2}$. This drop in solar radiation caused a short-term (1-hour) pronounced temperature rise in the uppermost layer of the sea down to $2 \mathrm{~m}$ depth. After the sharp drop in noon solar radiation, in the absence of water mixing, buoy measurements showed that the temperature rise in the uppermost layer of the Dead Sea took place for a shorter time and was more pronounced than the temperature rise under the regular diurnal solar cycle. The water heating could be explained by gravitational instability in the skin-surface layer, when the warm surface water with the increased salinity and density submerged, thereby increasing temperature in the layers below.
\end{abstract}

\section{Introduction}

The Dead Sea, a unique place on Earth, is located at approximately $415 \mathrm{~m}$ below sea level. This hypersaline terminal lake is $67 \mathrm{~km}$ long, up to $18 \mathrm{~km}$ wide, and $300 \mathrm{~m}$ in depth at its deepest point $[1,2]$. The Dead Sea lies within one of a series of basins aligned in a long $(600 \mathrm{~km})$ and narrow $(10-20 \mathrm{~km})$ tectonic valley, which branches northward from the trough of the Red Sea [3]. The Dead Sea is surrounded by the Judean Mountains to the west and by the Moab Mountains to the east (Figure 1). This area is characterized by changeable meteorological conditions, particularly by unsteady winds blowing along or across the valley. The wind regime in the Dead Sea Basin is governed by the general synoptic systems, such as Mediterranean cyclones, and by local factors, such as Mediterranean breezes and winds originating from topographic situations [4]. Hecht and Gertman [5] found that strong winds greater than $10 \mathrm{~m} / \mathrm{s}$ consisted of less than $1 \%$ of the wind observations at the Dead Sea. These winds were more prevalent in the winter than in the summer.
In the Dead Sea, solar radiation rapidly decreases with depth: at a depth of $2 \mathrm{~m}$, solar radiation is only $10 \%$ of its surface value [6]. Therefore, solar radiation heats mainly the 2-m uppermost layer of the Dead Sea. Infrared and microwave radiation is completely absorbed in the thin skin layer down to $2 \mathrm{~mm}$ [7].

Our knowledge of the thermal structure of the uppermost layer of the Dead Sea has been gained from measurements in situ $[1,5,8,9]$, as well as from remote sensing [10]. Despite the fact that solar radiation penetrates down to $2 \mathrm{~m}$ depth, temperature diurnal variations in the Dead Sea were observed at greater depths [10]. Near-surface temperature gradients of the air-sea interface result from three different processes: (1) absorption of solar radiation in the first meters, (2) heat loss to the atmosphere by evaporation and by emission of thermal radiation from the top millimeter of the sea, and (3) subsurface turbulent mixing [7].

The Dead Sea is one of the world's saltiest bodies of water: the salinity can reach $235 \mathrm{~g} / \mathrm{kg}$ [1]. Since the early 1980s, the Dead Sea has been halite supersaturated [11, 12]. 


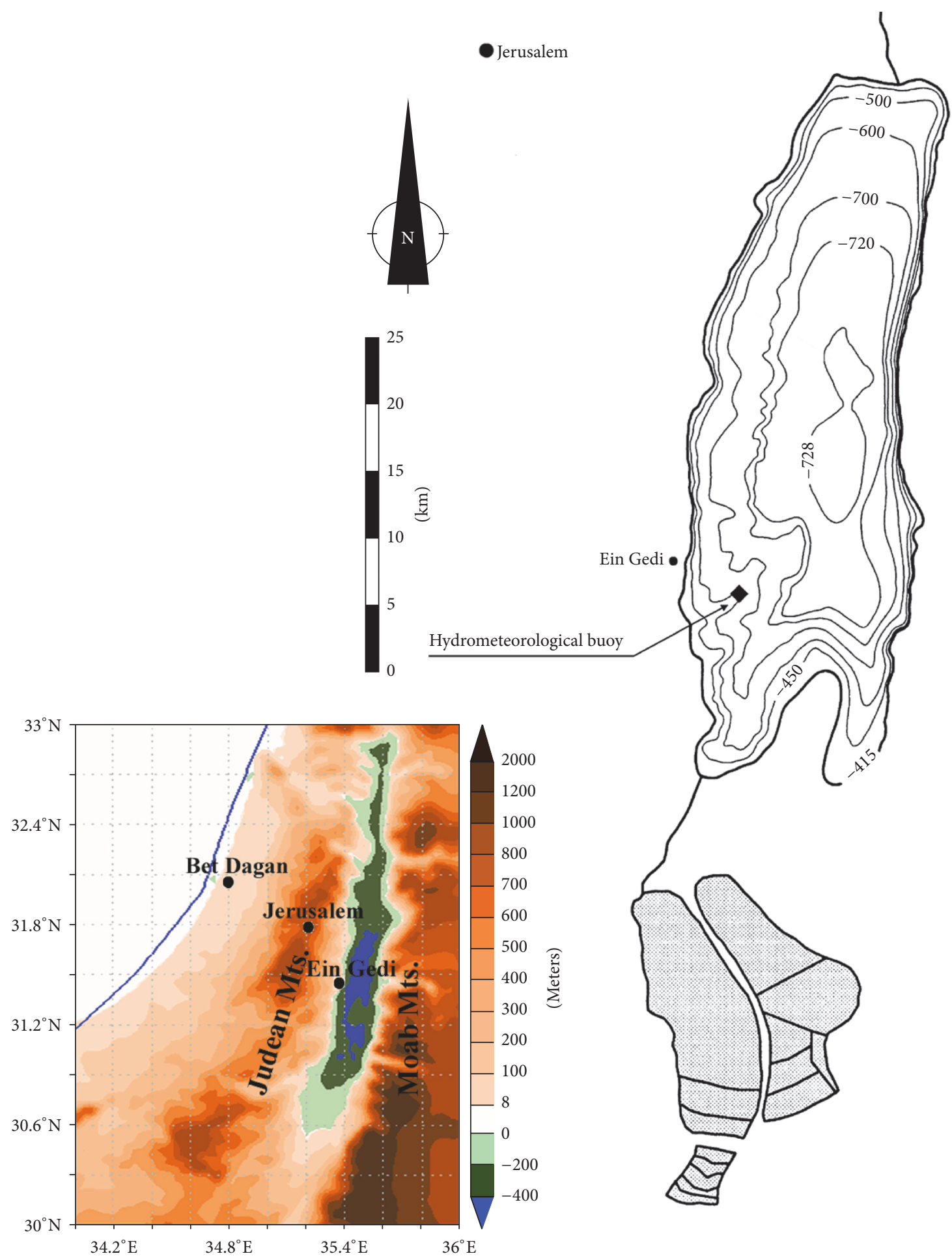

Figure 1: A map of the Dead Sea and surrounding areas with the location of three meteorological stations (Bet Dagan (32.01 $\mathrm{N}, 34.81^{\circ} \mathrm{E}$, 31 m.a.s.l.), Jerusalem $\left(31.78^{\circ} \mathrm{N}, 35.22^{\circ} \mathrm{E}, 810\right.$ m.a.s.l.), and Ein Gedi $\left(31.42^{\circ} \mathrm{N}, 35.39^{\circ} \mathrm{E},-415\right.$ m.a.s.l. $)$ ) and the Dead Sea buoy $\left(31.42^{\circ} \mathrm{N}, 35.44^{\circ} \mathrm{E}\right.$, -420 m.a.s.l.).

Massive amounts of halite precipitate as halite crystals causing changes in the chemical composition of the Dead Sea water [12, 13]. Arnon et al. [14] discussed the salt-fingering convection in the Dead Sea at a depth of approximately $25 \mathrm{~m}$, where the basic conditions for salt-fingering occurred. This salt-fingering at the depth of $\sim 25 \mathrm{~m}$ led to halite precipitation.

In the current study, we focused on observational evidence of a phenomenon of short-term $(\sim 1$ hour $)$ water 


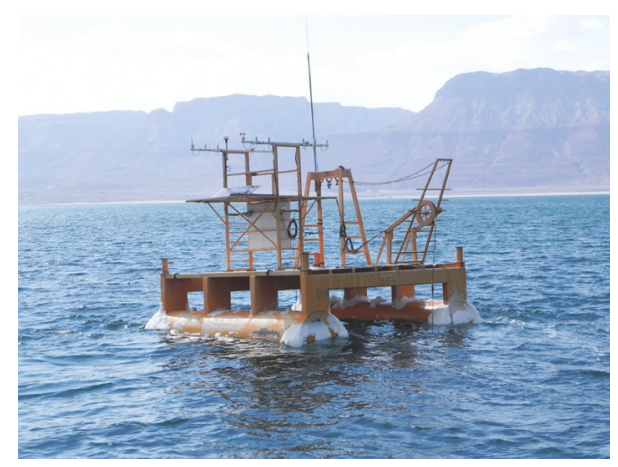

Figure 2: The Dead Sea hydrometeorological buoy.

heating in the uppermost layer of the Dead Sea after a sharp drop in solar radiation under weak winds. The heating occurred after the passage of an intensive Mediterranean cyclone with its frontal system over the Judean Mts. and over the Dead Sea on March 22, 2013. This passage was accompanied by clouds mixed with significant dust pollution and a foehn-like phenomenon over the Dead Sea valley. To our knowledge, such a phenomenon of short-term heating in the uppermost layer of the Dead Sea, following a sharp decrease in surface solar radiation, has not been discussed in previous publications.

This study was carried out in the framework of the DESERVE (DEad SEa Research Venue) project started in 2013 (https://www.deserve-vi.net/). This project aims at studying coupled lithospheric, hydrological, and atmospheric processes in the Dead Sea region.

\section{Method}

To study the effect of a sharp decrease in solar radiation on Dead Sea water heating, we used available meteorological and hydrographic measurements from a hydrometeorological buoy, anchored in the Dead Sea, and from three meteorological stations in Israel (Figure 1). The buoy was operated by the Israel Oceanographic and Limnological Research and located at approximately $5 \mathrm{~km}$ offshore from Ein Gedi (Figures 1 and 2). The exact position of the buoy was monitored by GPS. The measurements, collected at the hydrometeorological buoy at $3 \mathrm{~m}$ above the sea surface, included meteorological parameters such as air temperature, air pressure, relative humidity, and wind speed and direction, as well as incoming solar radiation (global radiation). Water temperatures were measured at $1,2,3,4,5,7,9,14,19,24,30$, and $40 \mathrm{~m}$ below sea level. Measurements were obtained at 20-minute intervals with an accuracy of $0.1^{\circ} \mathrm{C}$. All the measurements with the exception of wind speed were instantaneous. The measured wind speed was represented by both 20 -minute mean values and wind gusts. We also used 10 -minute standard meteorological measurements from the following three meteorological stations operated by the Israel Meteorological Service: Bet Dagan located near the Mediterranean coastline; Jerusalem located at the top of the Judean Mts.; and Ein Gedi located near the Dead Sea coastline (Figure 1).

\section{Sharp Decrease in Solar Radiation on March 22, 2013}

On March 22, 2013, a low-pressure system was observed over the Eastern Mediterranean, as illustrated by the spatial distribution of sea level pressure based on the NASA MERRA reanalysis data (Figures 3(a) and 3(b)). At 06 UTC, this low-pressure system was characterized by sea level pressure of approximately $995 \mathrm{hPa}$ at its center near Cyprus (hereafter the Cyprus low) (Figure 3(a)). It created favourable conditions for dust uplifting from the Eastern Sahara and transport by southwest winds into the Eastern Mediterranean (Figure 3(c)). Then, this Cyprus low with its frontal system shifted eastward, followed by increasing strong southwesterly to westerly winds over Israel. At 12 UTC, this low-pressure system was characterized by sea level pressure below $995 \mathrm{hPa}$ at its center near Cyprus (Figure 3(b)). The passage of the Cyprus low with its frontal system over Israel toward the Dead Sea valley was accompanied by a large amount of dust pollution (Figure $3(\mathrm{~d})$ ) and by significant cloudiness observed from space by the MODIS spectroradiometer on board the NASA Aqua satellite (Figure 3(e)).

The presence of desert dust is illustrated by dust forecasts from the operational TAU/DREAM dust model, showing $10 \mathrm{~m}$ winds and surface dust concentration at 6 UTC and 12 UTC (Figures 3(c) and 3(d)) on March 22. On this date, available monitoring sites in the southern part of the Dead Sea, which measure concentration of total suspended particles (TSP), showed extremely high TSP concentrations $\left(\sim 7000 \mu \mathrm{g} \mathrm{m}^{-3}\right)$ of two orders of magnitude higher than their annual mean values [15].

Details of the passage of frontal clouds over the Dead Sea were analysed using radar measurements of cloud heights (Figure 4). This radar (C-band with the $5 \mathrm{~cm}$ wavelength) is operated by the Israel Meteorological Service and located at Bet Dagan, near the Mediterranean coast (Figure 1). At 9 UTC, west winds brought significant cloudiness to the upwind side of the Judean Mts. Radar showed multilayer clouds characterized by cloud top heights from 1.5 to $\sim 8 \mathrm{~km}$, although, the clear-sky conditions still remained on the downwind side of the mountain ridge (Figure 4). One hour later clouds of top height from $3-4 \mathrm{~km}$ covered the Dead Sea. At 10:30 UTC, the Dead Sea was covered by frontal multilayer clouds of top heights from 1.5 to $\sim 8 \mathrm{~km}$ (Figure 4 ). Solar radiation (SR), measured by the pyranometer at Dead Sea hydrometeorological buoy, shows an essential decrease in measured SR during the passage of frontal clouds accompanied by dust pollution.

Figure 5 compares solar radiation reaching the surface over the Israel Mediterranean coast, over the Judean Mts., and over the Dead Sea. In particular, in Bet Dagan, the maximum solar radiation of $780 \mathrm{~W} \mathrm{~m}^{-2}$ was observed at 08:10 UTC and the minimum solar radiation of $100 \mathrm{~W} \mathrm{~m}^{-2}$ was observed at 09:40 UTC (Figure 5). In the Dead Sea, the maximum solar radiation of $860 \mathrm{~W} \mathrm{~m}^{-2}$ was observed at 09:40 UTC, close to local noon at $10 \mathrm{UTC}$. Then the solar radiation sharply dropped to $160 \mathrm{~W} \mathrm{~m}^{-2}$ at 10:20 UTC, followed by a further gradual decrease to $50 \mathrm{~W} \mathrm{~m}^{-2}$ by 12:00 UTC (Figure 5). Solar 

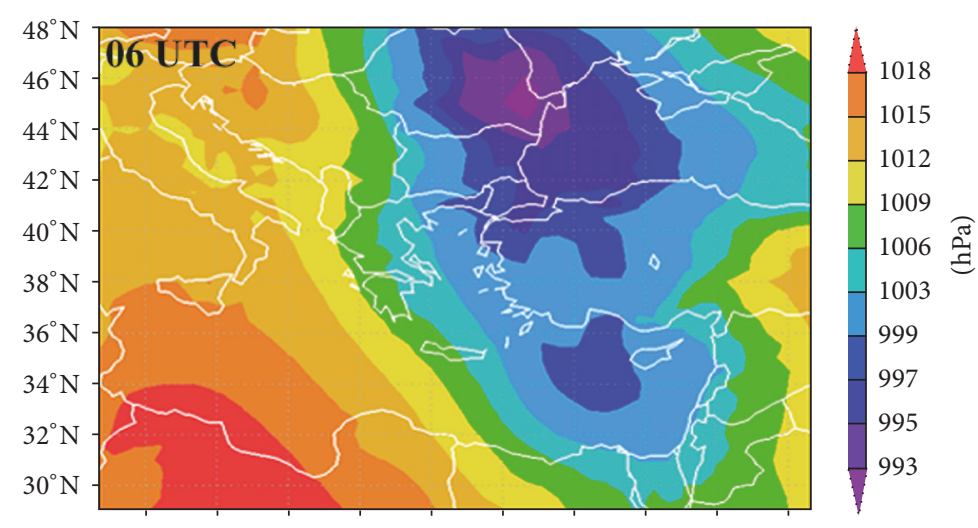

$12^{\circ} \mathrm{E} \quad 15^{\circ} \mathrm{E} \quad 18^{\circ} \mathrm{E} \quad 21^{\circ} \mathrm{E} \quad 24^{\circ} \mathrm{E} \quad 27^{\circ} \mathrm{E} \quad 30^{\circ} \mathrm{E} \quad 33^{\circ} \mathrm{E} \quad 36^{\circ} \mathrm{E} \quad 39^{\circ} \mathrm{E}$

(a)
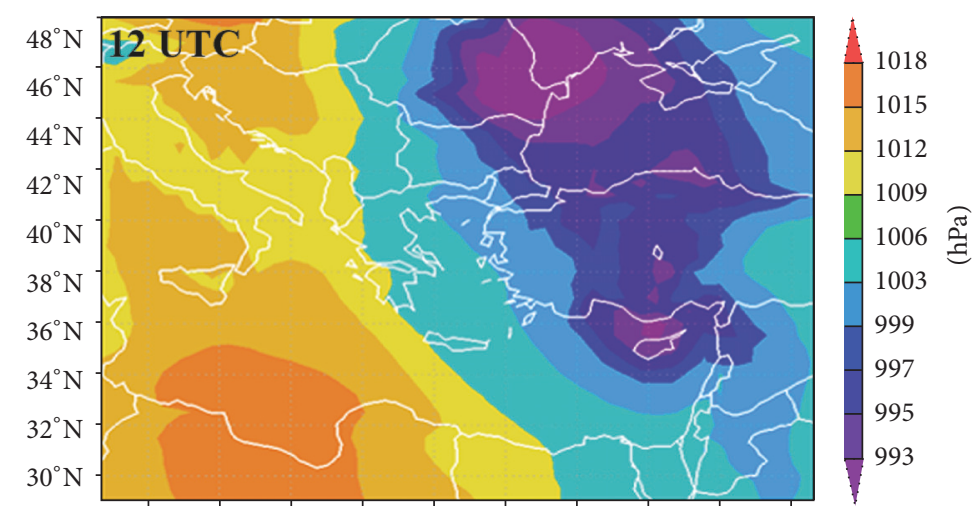

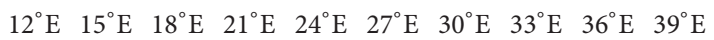

(b)
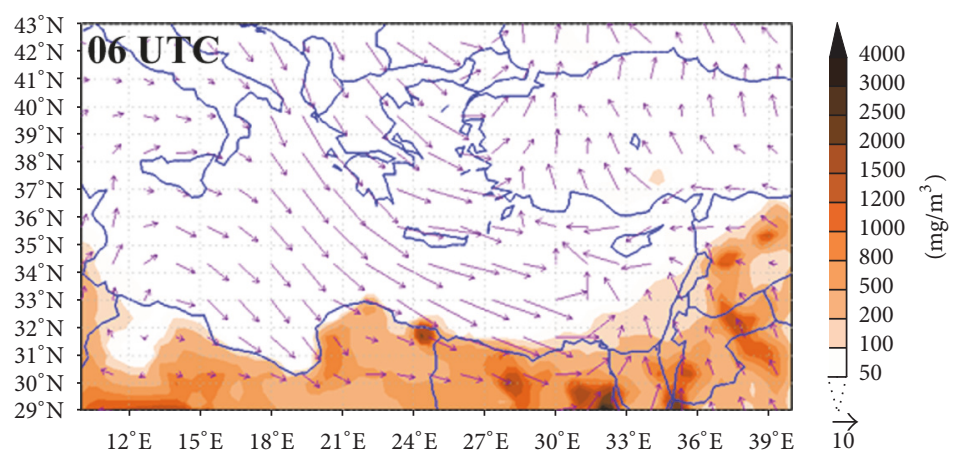

(c)

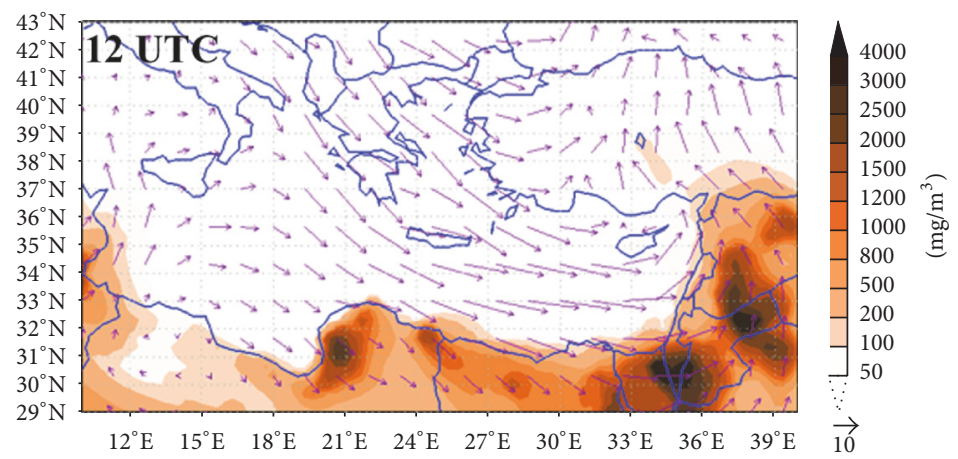

(d)

FIgure 3: Continued. 


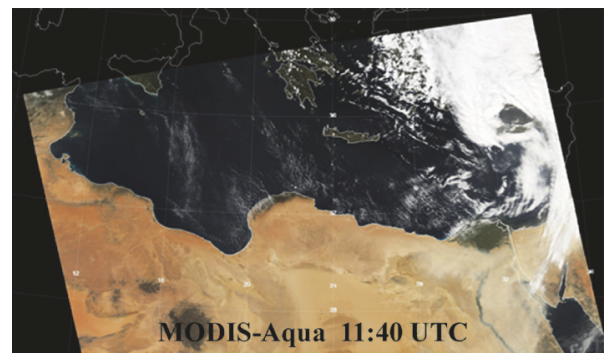

(e)

FIGURE 3: ( $\mathrm{a}$ and b) Maps of sea level pressure on March 22, 2013, at (a) 06 UTC and (b) 12 UTC, based on NASA MERRA reanalysis data. (c and d) Maps of 10-m winds and surface dust concentration at (c) 06 UTC and (d) 12 UTC, based on DREAM dust model data. (e) MODIS-Aqua satellite image of cloudiness taken on March 22, 2013, at 11:40 UTC.

radiation measurements showed that the transition from clear-sky to overcast conditions was sharper over the Dead Sea than over the Israel Mediterranean coast (Bet Dagan).

\section{Air Temperature Variations after the Sharp Decrease in Solar Radiation}

A sharp decrease in solar radiation due to dust pollution and overcast conditions led to a sharp decrease of approximately $10^{\circ} \mathrm{C}$ in surface air temperature over Israel on March 22, 2013 (as illustrated by temperature measurements in Bet Dagan and Jerusalem (Figure 5)), with the exception of the Dead Sea. In Ein Gedi (located near the Dead Sea coastline) the air temperature dropped much less significantly than in Bet Dagan and Jerusalem (from $28.7^{\circ} \mathrm{C}$ at $10: 10 \mathrm{UTC}$ to $26.8^{\circ} \mathrm{C}$ at 10:40 UTC) (Figure 5). At the Dead Sea, buoy measurements showed that the air temperature was not sensitive at all to this sharp decrease in solar radiation (Figure 5). Note that, over the Dead Sea, the sharp decrease in solar radiation took place under weak winds with speed of less than $3 \mathrm{~m} \mathrm{~s}^{-1}$ (Figure 6). Therefore, the buoy measurements provide us with observational evidence that, under weak winds, air temperature near the surface of the Dead Sea is mainly determined by sea surface temperature and not by short-term changes in solar radiation. Moreover, despite the significant decrease in solar radiation over the Dead Sea, the surface air temperature, measured at the buoy, surprisingly increased one hour later from $25.4^{\circ} \mathrm{C}$ at 10:40 UTC to approximately $30^{\circ} \mathrm{C}$ at 12:00 UTC (Figure 5). This increase in air temperature was accompanied by a decrease in relative humidity from $38 \%$ to $20 \%$. This decrease in relative humidity in the bottom of the valley, accompanied by the increase in air temperature, is a characteristic feature of the foehn phenomenon produced by strong west winds blowing across the Judean Maintains [16]. Concurrently, an increase in air temperature was observed in Ein Gedi, near the Dead Sea shoreline (Figure 5). The appearance of this hot, dry air was accompanied by strong western foehn winds blowing along the lee side of the Judean Mts. [16]. Buoy measurements showed that winds significantly increased from $2.5 \mathrm{~m} \mathrm{~s}^{-1}$ (wind gusts up to $3 \mathrm{~m} \mathrm{~s}^{-1}$ ) at 11 UTC to $11 \mathrm{~m} \mathrm{~s}^{-1}$ (wind gust up to $20 \mathrm{~m} \mathrm{~s}^{-1}$ ) at 12:40 UTC (Figure 6).

\section{Buoy Measurements of Water Temperature after the Sharp Decrease in Solar Radiation}

On March 22, after sunrise and until the drop in solar radiation, the water temperature at a depth of $1 \mathrm{~m}$ was noticeably higher than that at a depth of $2 \mathrm{~m}$, based on buoy measurements (Figure 7). This took place under observed weak winds of approximately $2.5 \mathrm{~m} / \mathrm{s}$ (Figure 6). Therefore, the aforementioned temperature stratification in the presence of solar radiation is evidence that these weak winds were incapable of producing significant mixing in the $2 \mathrm{~m}$ uppermost layer. After the dramatic drop in noon solar radiation, buoy measurements unexpectedly showed an increase in water temperature at $1 \mathrm{~m}$ depth (Tw1) from $24.1^{\circ} \mathrm{C}$ at 10:20 UTC to $25^{\circ} \mathrm{C}$ at 11:40 UTC and an increase at $2 \mathrm{~m}$ depth (Tw2) from $23.9^{\circ} \mathrm{C}$ to $24.4^{\circ} \mathrm{C}$ (Figures 6 and 7 ). Note that, despite the drop in noon solar radiation, the maximum temperature Tw1 = $25^{\circ} \mathrm{C}$ on the day under study, March 22, was even higher than the maximum temperature $\mathrm{Tw} 1=24.7^{\circ} \mathrm{C}$ on the previous day March 21 (Figure 6). This occurred under the same level of noon solar radiation and under similar weak winds in these two consecutive days. This illustrates that the heating in the uppermost layer of the Dead Sea, following the sharp drop in noon solar radiation, took place for shorter time and was even more pronounced than the heating under the full regular diurnal solar cycle.

It is worth noting that the most pronounced heating at a depth of $1 \mathrm{~m}$ (Tw1) from 10:20 UTC $\left(24.1^{\circ} \mathrm{C}\right)$ to 10:40 UTC $\left(24.5^{\circ} \mathrm{C}\right)$ took place at approximately the same temperature rate as that at a depth of $2 \mathrm{~m}$ (Tw2) from 11:20 UTC $\left(24.0^{\circ} \mathrm{C}\right)$ to $11: 40\left(24.4^{\circ} \mathrm{C}\right)$. As seen above, this heating at $2 \mathrm{~m}$ depth occurred with a 1-hour delay compared to the heating at $1 \mathrm{~m}$ depth.

Buoy measurements showed that, after the drop in solar radiation, the temperature rise at the layers deeper than $2 \mathrm{~m}$ was also observed, although it was less pronounced than that above $2 \mathrm{~m}$ (Figure 7). The heat transfer to deep layers occurred with a delay in time at each stage: the time delay in the maximum temperature with increasing depth is clearly seen in the buoy data.

At 11:40 UTC, under winds of approximately $5 \mathrm{~m} \mathrm{~s}^{-1}$ (with wind gusts up to $7.2 \mathrm{~m} \mathrm{~s}^{-1}$ ), mechanical mixing in the $2 \mathrm{~m}$ 

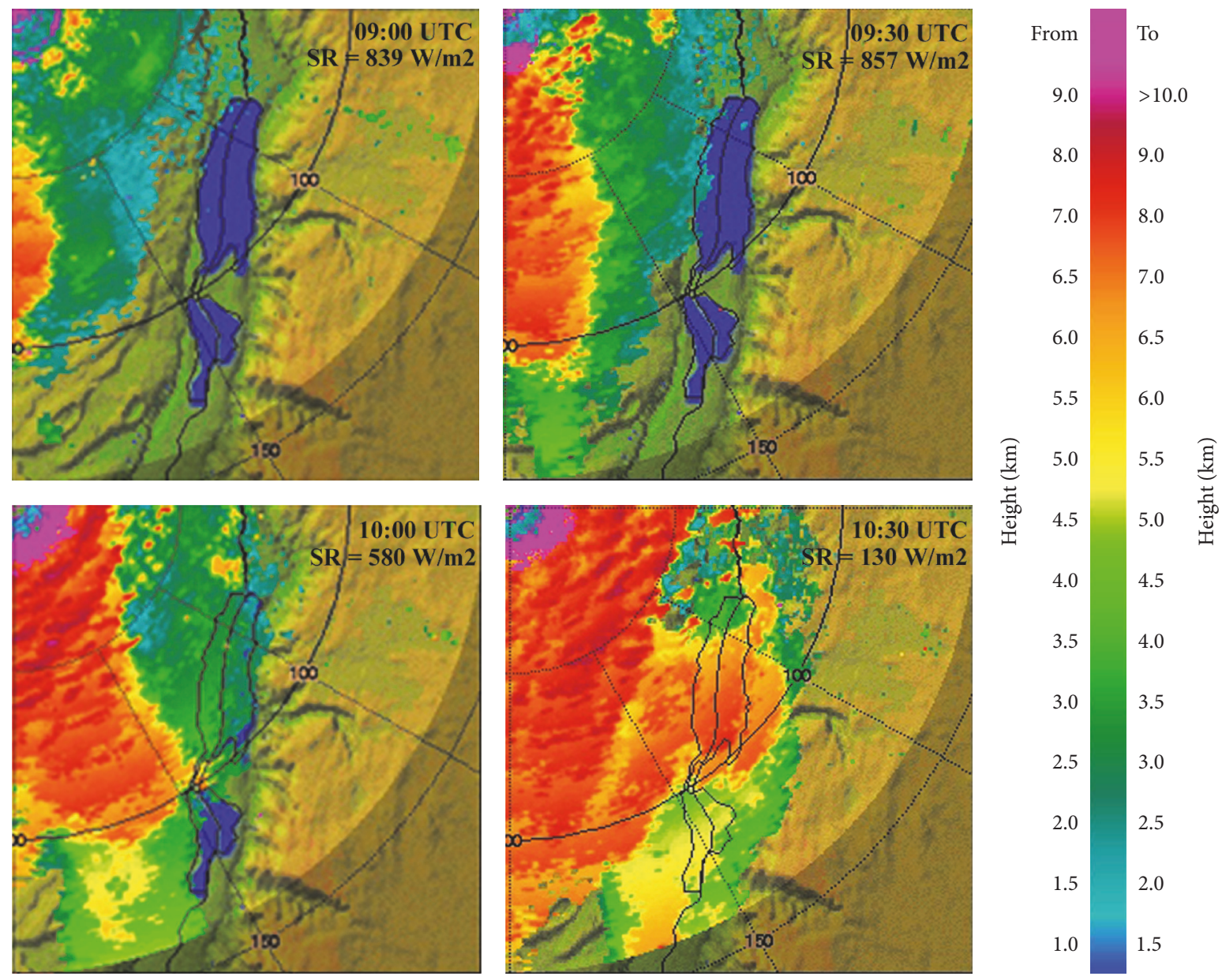

FIGURE 4: Radar measurements of cloud top height from 09:00 UTC to 10:30 UTC on March 22, 2013. Solar radiation (SR), measured by the pyranometer at the hydrometeorological buoy anchored in the Dead Sea, is represented by the numbers at any specified time moment.

uppermost layer of the Dead Sea arose. As a result of mechanical mixing between the upper warm layer and the lower cool layer, the upper warm layer becomes colder while the lower cold layer becomes warmer. This mixing switched off the mechanism of heating in the $2 \mathrm{~m}$ uppermost layer of the Dead Sea. Specifically, by 12 UTC, Twl decreased to $24.8^{\circ} \mathrm{C}$, while simultaneously Tw2 reached its maximum of $24.6^{\circ} \mathrm{C}$ (Figure 7). From 12 UTC to $12: 40$ UTC, winds increased from $5 \mathrm{~m} \mathrm{~s}^{-1}$ to $11 \mathrm{~m} \mathrm{~s}^{-1}$ (wind gusts from $8.4 \mathrm{~m} \mathrm{~s}^{-1}$ to $20 \mathrm{~m} \mathrm{~s}^{-1}$ ) (Figure 6). These strong winds were able to mix water to a depth of $4 \mathrm{~m}$, because of mechanical mixing. Specifically, by 12:40 UTC, Tw1 and Tw2 simultaneously decreased from approximately $24.6^{\circ} \mathrm{C}$ at $12 \mathrm{UTC}$ to $24.3^{\circ} \mathrm{C}$ at 12:40 UTC. At the same time, Tw3 and Tw4 increased from approximately $23.9^{\circ} \mathrm{C}$ at $12 \mathrm{UTC}$ to $24.2^{\circ} \mathrm{C}$ at $12: 40 \mathrm{UTC}$ (Figure 7). By 24 UTC, the water temperature equalized in all layers down to $14 \mathrm{~m}$.

As mentioned in Section 2, water temperature was measured by the Dead Sea buoy with an accuracy of $0.1^{\circ} \mathrm{C}$. On March 22, 2013, after the sharp drop in solar radiation, buoy observations showed an increase in Twl of $1^{\circ} \mathrm{C}$ and in Tw2 of $0.5^{\circ} \mathrm{C}$, which indicates they are reliable. To remove the unwanted noisy component from the buoy temperature data, a moving average filter can be used, which is optimal for filtering random noise, while retaining a signal under investigation. In our study, a 3-point moving average filter was applied to $20 \mathrm{~min}$ row data. Figure 8(a) represents the buoy temperature data after filtering the noisy component. One can see that, from 8 UTC to the sharp drop in solar radiation at 9:40 UTC, there were some insignificant changes in Tw1 and Tw2. After this sharp drop, a pronounced increase was observed in Tw1 and Tw2 (Figures 8(a) and 8(b)).

\section{Plausible Mechanism of Formation of Pronounced Heating in the Top Layer of the Dead Sea}

The pronounced temperature rise in the $2 \mathrm{~m}$ uppermost layer of the Dead Sea, on March 22, 2013, cannot be explained by mechanical water mixing under the observed weak winds of less than $2.5 \mathrm{~m} / \mathrm{s}$ (Figure 6). This is because of the simultaneous temperature rise at the depth of $1 \mathrm{~m}$ and $2 \mathrm{~m}$ during the two-hour period from 9:40 UTC to 11:40 UTC (Figure 7). By contrast, the appearance of strong winds of up to $20 \mathrm{~m} / \mathrm{s}$ 

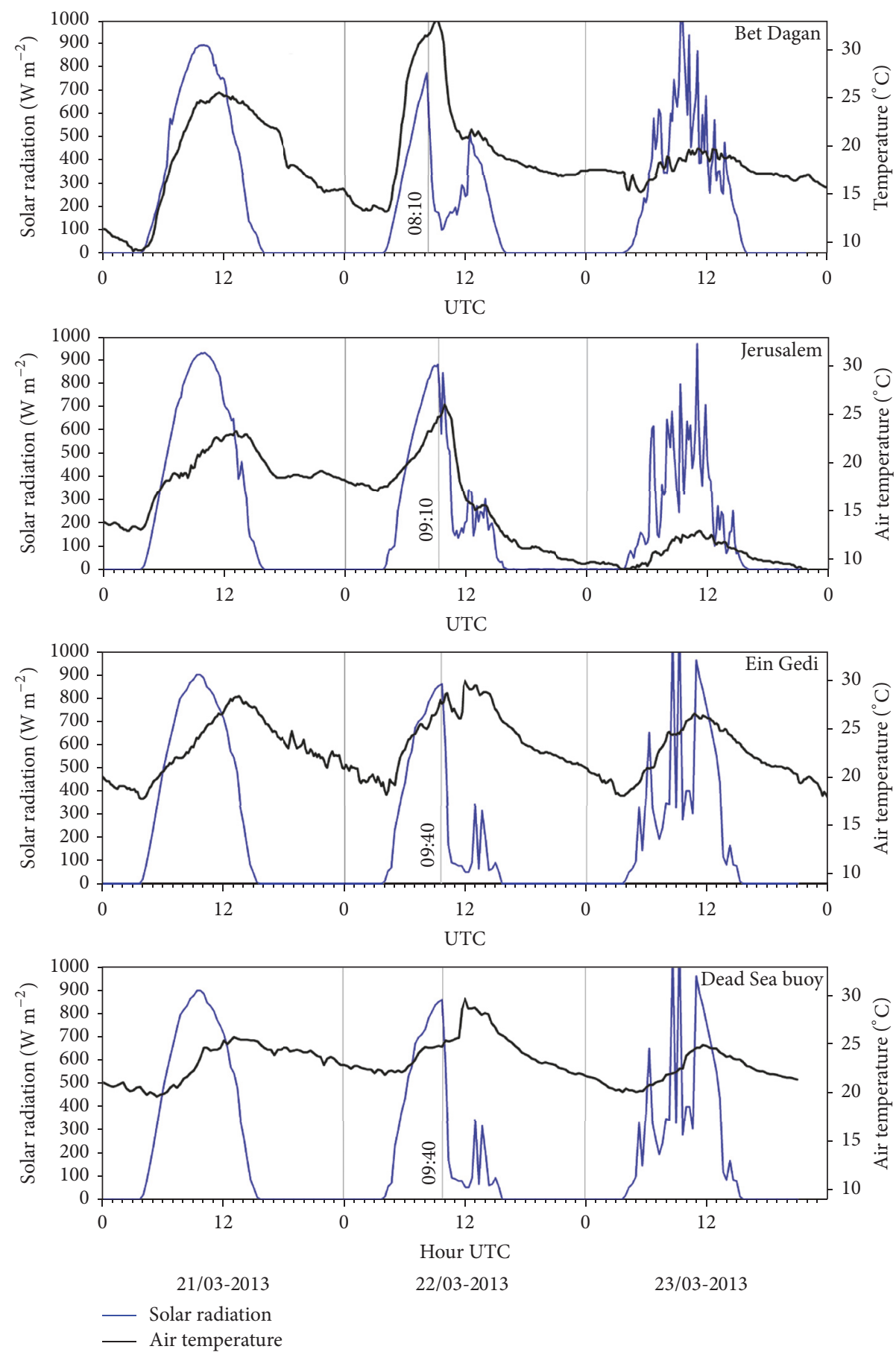

FIGURE 5: Measurements of (black lines) near-surface air temperature together with (blue lines) solar radiation during the period March 21-23, 2015, at the monitoring sites in Bet Dagan, Jerusalem, Ein Gedi, and Dead Sea buoy. The vertical lines designate the specified times (UTC) of maximum solar radiation on March 22, 2016, at different monitoring sites.

after 11:40 UTC led to mechanical mixing and, consequently, to water temperature equalizing at the depth of $1 \mathrm{~m}$ and $2 \mathrm{~m}$. As an additional illustration, Figure 6 represents the case of mechanical mixing, observed on March 23, 2013, under strong winds, when water temperature equalized at all depths in the uppermost layer of the Dead Sea.
Moreover, neither thermal conductivity nor horizontal advection of warm water could explain the observed phenomenon. Heating of seawater by thermal conductivity is a slow process, which could be effective for some long-term phenomena such as weekly or monthly changes, but not for the short-term (1 hour) temperature rise observed on the 

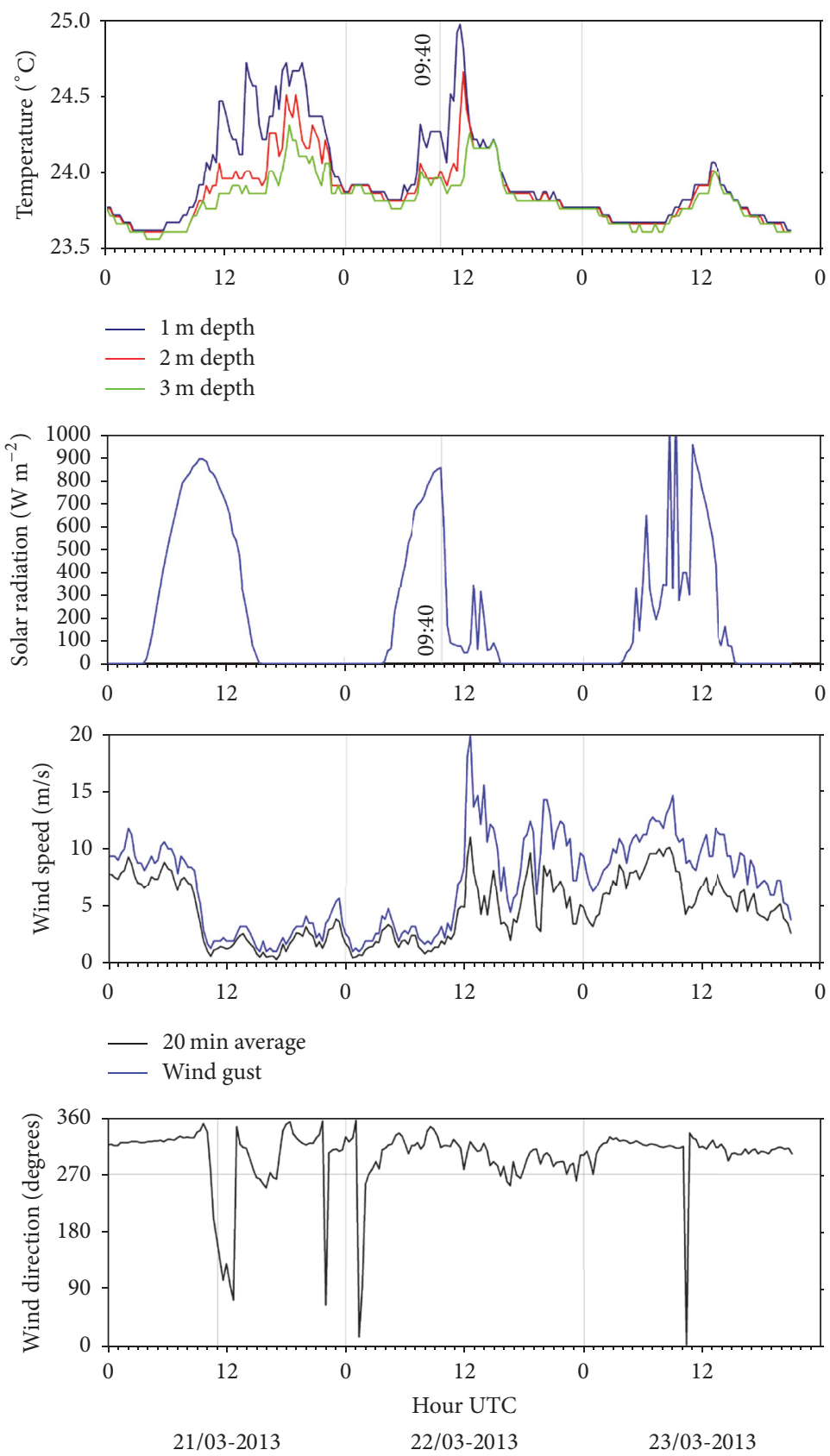

FIGURE 6: Measurements of sea water temperature and meteorological parameters at the Dead Sea buoy from March 21 to March $23,2013$.

specified day. Horizontal advection of warm water also could not explain the phenomenon under consideration. As shown in Figures 9(a) and 9(b), on March 22, from 7:40 UTC to the maximum in solar radiation at 9:40 UTC, there was no noticeable increase in Tw1 and Tw2, despite the observed increase in solar radiation. Starting at 9:40 UTC on March 22, under weak winds of less than $2.5 \mathrm{~m} / \mathrm{s}$, it is highly unlikely that the observed pronounced increase in Tw1 and Tw2 following the sharp drop in solar radiation was caused by some surge of warm water, which suddenly occurred and propagated to the depth of $2 \mathrm{~m}$ and even deeper. It is even more unlikely that the heating at a depth of $2 \mathrm{~m}$ with the most pronounced temperature rate occurred with a 1-hour delay compared to that at a depth of $1 \mathrm{~m}$.

In the Dead Sea, solar radiation (SR) heats mainly the $2 \mathrm{~m}$ uppermost layer: at a depth of $0.5 \mathrm{~m}$, SR is $\sim 50 \%$ of its surface value; at a depth of $1 \mathrm{~m}, \mathrm{SR}$ is $\sim 30 \%$ of its surface value; and at a depth of $2 \mathrm{~m}, \mathrm{SR}$ is only $10 \%$ of its surface value [6]. This explains the observed temperature stratification at depths in the $2 \mathrm{~m}$ top layer of the Dead Sea; consequently, the gravitational stability in the presence of solar radiation took place (Figure 7). 

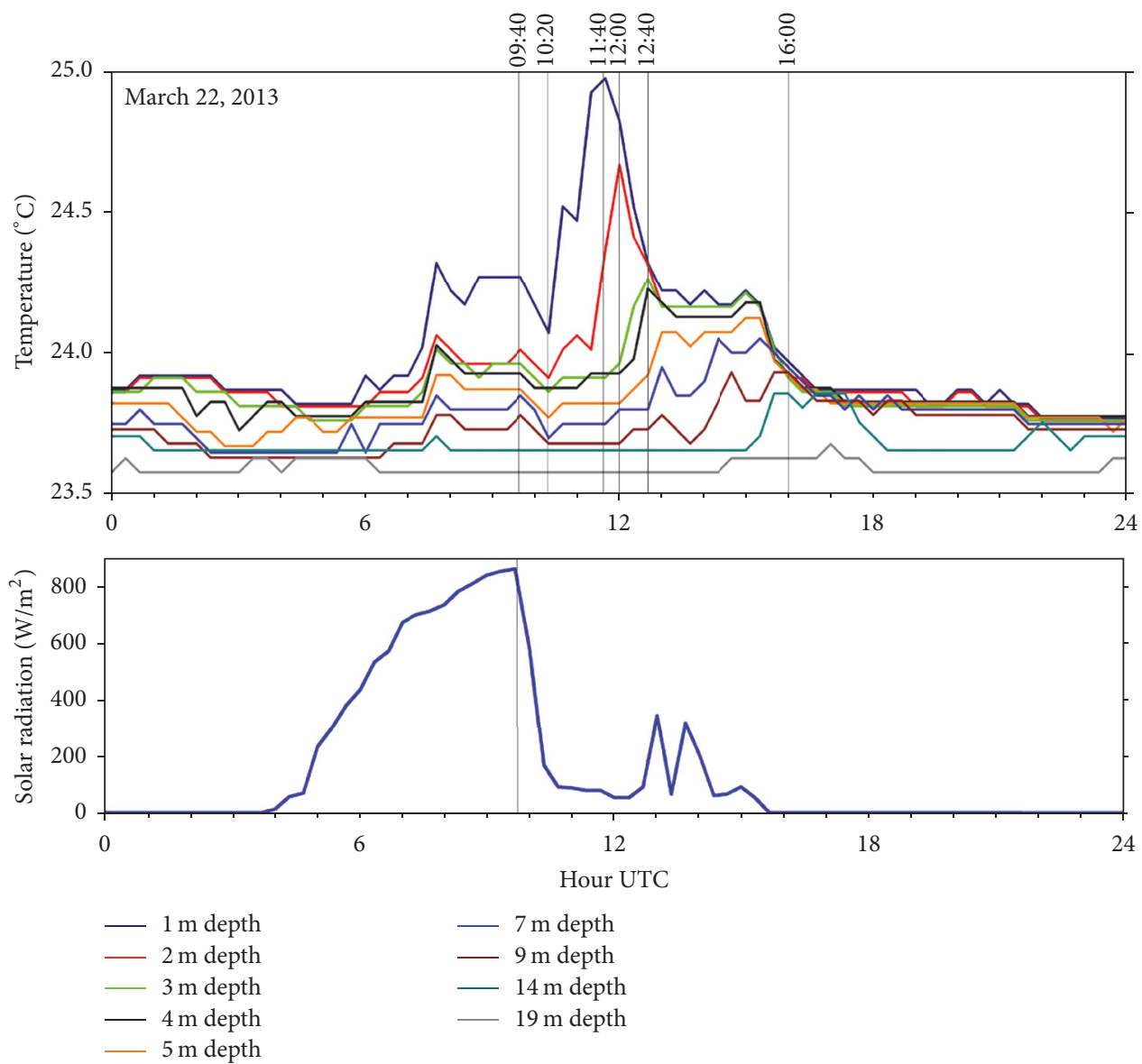

Figure 7: Measurements of seawater temperature and solar radiation at the Dead Sea buoy on March 22, 2013. The vertical lines designate the specified times in UTC.

We consider that the following plausible mechanism could explain the observed short-term heating in the uppermost layer of the Dead Sea, following the sharp drop in noon solar radiation on the specified day under study. Let us consider the following two-layer structure in the Dead Sea: a thin surface layer, where evaporation takes place, with water density D1, and a similar thin layer below with water density D2. Following a sharp drop in solar radiation on March 22, evaporation from the thin surface layer of the Dead Sea led to water cooling accompanied by an increase in water salinity in this layer. As a result, the water density in this thin surface layer became higher than the density in the layer below D1 > D2. Thus, the drop in solar radiation caused conditions for gravitational instability in the thin surface layer. As a result of this instability, the warm dense surface water submerged, thereby increasing temperature in the layers below.

The above-mentioned mechanism is based on previous experimental and theoretical studies of gravitational instability in fresh water induced by evaporative cooling at the top surface. In particular, Spangenberg and Rowland [17] investigated this phenomenon in a series of experiments. They experimentally showed that, when an initially homogeneous layer of fluid is cooled at the top surface by evaporation, a cold dense layer of fluid forms at this top surface. This top surface layer becomes unstable (because of its higher density than in the layer below) and plunges in vertical sheets. Thus, the fluid suddenly begins to manifest convective behaviour [17]. Forster [18] theoretically analysed the results of the experiments conducted by Spangenberg and Rowland [17]. Spangenberg and Rowland showed that when the convective circulation (induced by gravitational instability) started, the Rayleigh number exceeded some critical value of the order $10^{3}$.

In the case of the Dead Sea on March 22, 2013, after the sharp decrease in solar radiation, we also have a thin surface layer, which is cooled by evaporation (leading to an increase in density of this surface layer and, consequently, gravitational instability). As estimated by Steinhorn [19], the evaporation rate for the Dead Sea hypersaline water is approximately $40 \%$ higher than that for fresh water. Consequently, water cooling due to evaporation for the Dead Sea water is more intensive than that for fresh water.

Not only does water density in the Dead Sea surface layer increase due to cooling, but also it increases due to increasing salinity as a result of evaporation. Thus, the formation of gravitational instability in the Dead Sea thin surface layer after the sharp drop in solar radiation is indeed plausible.

According to Stern [20], in seawater, the molecular diffusivity of heat is two orders of magnitude higher than the diffusivity of salt. This means that, as a result of this low 


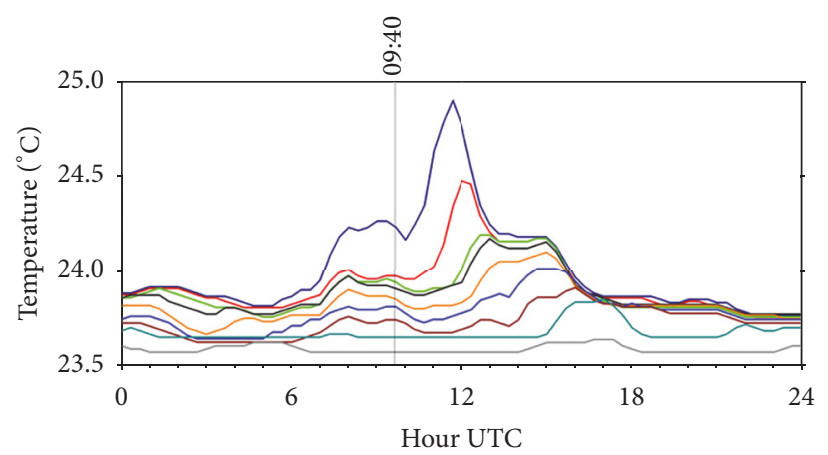

(a)

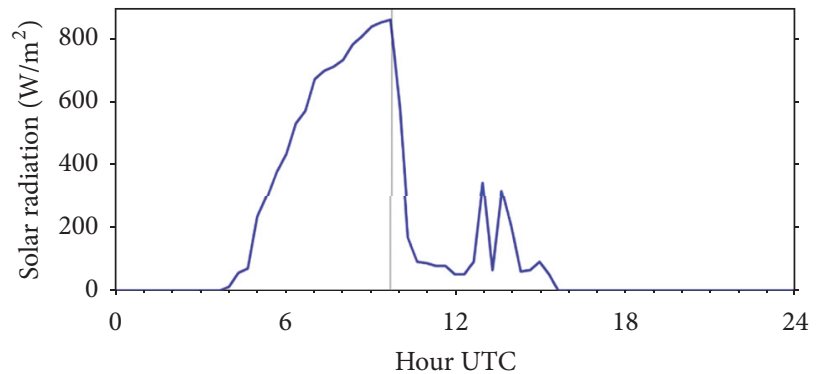

$1 \mathrm{~m}$ depth
$-\quad 2 \mathrm{~m}$ depth
$-3 \mathrm{~m} \mathrm{depth}$
$+\quad 4 \mathrm{~m} \mathrm{depth}$
$-5 \mathrm{~m} \mathrm{depth}$

$$
\begin{aligned}
& 7 \mathrm{~m} \text { depth } \\
& \hline \quad 9 \mathrm{~m} \text { depth } \\
& -14 \mathrm{~m} \mathrm{depth} \\
& -19 \mathrm{~m} \mathrm{depth}
\end{aligned}
$$

(b)

Figure 8: (a) The buoy temperature data after filtering the noisy component; (b) buoy measurements of solar radiation on March 22, 2013. The vertical line designates the specified times (UTC) of maximum solar radiation.

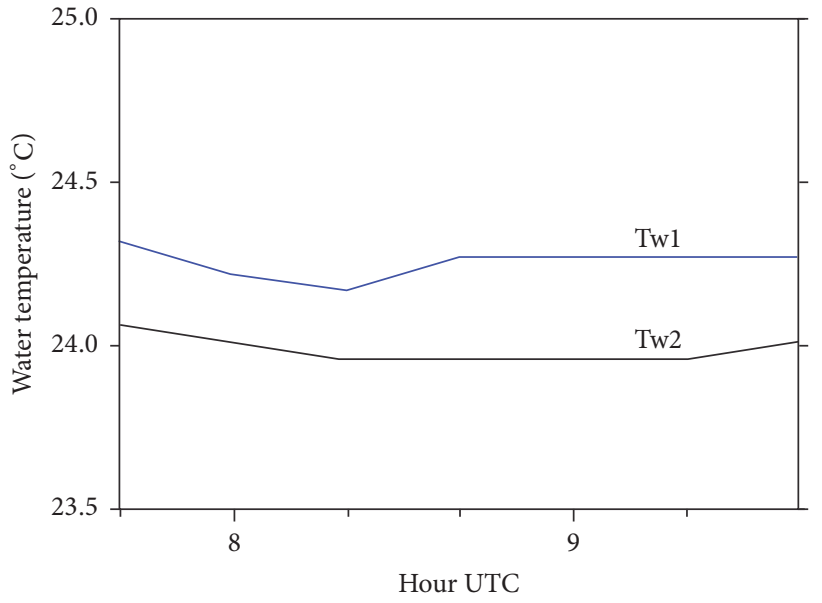

(a)

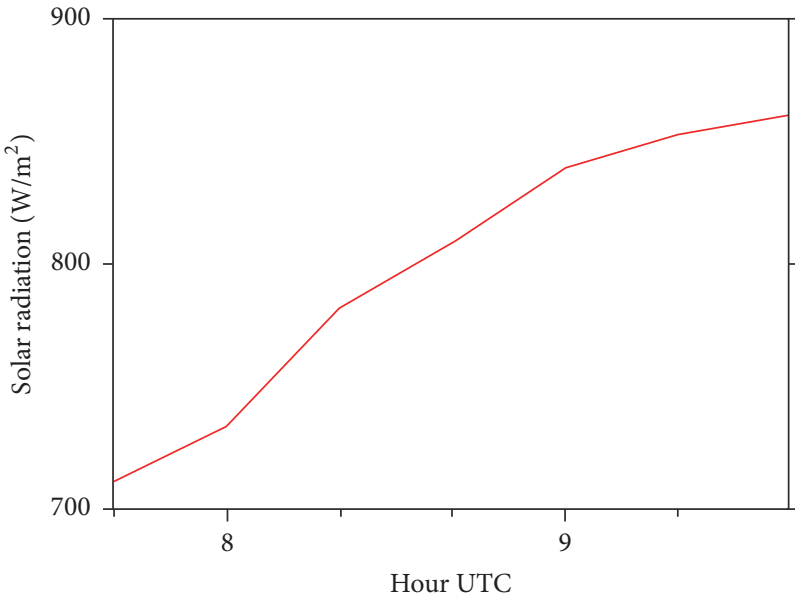

(b)

Figure 9: Measurements of (a) sea water temperature at $1 \mathrm{~m}$ (Tw1) and $2 \mathrm{~m}$ (Tw2) depth and (b) solar radiation near its maximum during the 2-hour period from 7:40 UTC to 9:40 UTC at the Dead Sea buoy on March 22, 2013.

diffusivity of salt, the salinity of the submerging layer remains invariable during the submergence process. This explains the submerging process of warm salt surface water within cooler water in the layers below.
In accordance with Stern [20], laboratory experiments showed that the speed of descent of warm salt water within cooler fresh water was approximately $40 \mathrm{~cm} /$ hour. In the case of the Dead Sea on March 22, 2013, after the sharp decrease 
in solar radiation, we observed that the most pronounced heating at a depth of $1 \mathrm{~m}$ (Tw1) from 10:20 UTC $\left(24.1^{\circ} \mathrm{C}\right)$ to 10:40 UTC $\left(24.5^{\circ} \mathrm{C}\right)$ took place at approximately the same temperature rate as the heating at a depth of $2 \mathrm{~m}$ (Tw2) from $11: 20 \mathrm{UTC}\left(24.0^{\circ} \mathrm{C}\right)$ to $11: 40\left(24.4^{\circ} \mathrm{C}\right)$. This heating at $2 \mathrm{~m}$ depth occurred with a 1-hour delay compared to the heating at $1 \mathrm{~m}$ depth. This 1-hour delay indicates that the speed of descent of Dead Sea warm dense surface water within cooler water in the layers below was approximately $100 \mathrm{~cm} /$ hour. This speed is the same order as the above-mentioned speed observed in laboratory experiments. This process explains why the submerging warm salt surface water could heat water in the layers below, being the reason for the observed shortterm temperature rise at a depth of $1 \mathrm{~m}$ and $2 \mathrm{~m}$ following the drop in noon solar radiation.

\section{Conclusions}

In our study we present observational evidence of an unexpected short-term (1-hour) pronounced temperature rise in the uppermost layer of the Dead Sea under weak winds: this followed a sharp drop in solar radiation due to clouds mixed with significant dust pollution over the region on March 22, 2013. This evidence was based on Dead Sea buoy measurements. After the sharp drop in noon solar radiation, in the absence of water mixing, buoy measurements showed that the temperature rise in the uppermost layer took place for a much shorter time and was even more pronounced than the temperature rise under the full regular diurnal solar cycle.

We consider that the phenomenon of short-term heating in the uppermost layer of the Dead Sea can occur at times, but it usually remains unobserved. This is why this phenomenon has not been discussed so far in previous publications.

Specific meteorological conditions (caused the sharp drop in solar radiation on the date under study) and the temperature stratification in the uppermost layer of the Dead Sea allowed us to detect this phenomenon of short-term heating. Under such conditions, in the absence of solar radiation, continuing strong evaporation caused an increase in water density in the thin surface layer due to cooling and increasing salinity. This led to the gravitational instability in this surface layer causing the dense surface water to submerge. As a result of low diffusivity of salt, the salinity of the submerging layer remained invariable during the submergence process. This explains the submerging process of warm salt surface water within cooler water in the layers below and the pronounced heating in the $2 \mathrm{~m}$ uppermost layer of the Dead Sea.

To better understand the observed phenomenon of shortterm heating, it would be essential to conduct further research in the Dead Sea and other hypersaline lakes using observational, model, and theoretical approaches.

\section{Disclosure}

The results of the current study were presented at the General Assembly of the European Geophysical Union in 2016 [21].

\section{Conflicts of Interest}

The authors declare that there are no conflicts of interest regarding the publication of this paper.

\section{Acknowledgments}

The authors would like to acknowledge the Israel Meteorological Service for providing them with meteorological data taken at Bet Dagan, Jerusalem, and Ein Gedi. The Tel Aviv University team acknowledges support from the international Virtual Institute DESERVE (DEad SEa Research Venue), funded by the German Helmholtz Association. The authors express their gratitude to Gregory Falkovich from the Weizmann Institute of Science for helpful discussions.

\section{References}

[1] I. Gertman and A. Hecht, "The Dead Sea hydrography from 1992 to 2000," Journal of Marine Systems, vol. 35, no. 3-4, pp. 169-181, 2002.

[2] E. Boss, H. Gildor, W. Slade, L. Sokoletsky, A. Oren, and J. Loftin, "Optical properties of the Dead Sea," Journal of Geophysical Research: Oceans, vol. 118, no. 4, pp. 1821-1829, 2013.

[3] D. Neev and K. O. Emery, "The Dead Sea, depositional processes and environments of evaporates," Geological Survey of Israel Bulletin, vol. 41, pp. 1-147, 1967.

[4] H. Shafir and P. Alpert, "Regional and local climatic effects on the Dead-Sea evaporation," Climatic Change, vol. 105, no. 3-4, pp. 455-468, 2011.

[5] A. Hecht and I. Gertman, "Dead sea meteorological climate," in Fungal Life in the Dead Sea, E. Nevo, A. Oren, and S. P. Wasser, Eds., pp. 68-114, Gantner, Oberreifenberg, Germany, 2003.

[6] A. Oren and M. Shilo, "Population dynamics of Dunaliella parva in the Dead Sea," Limnology and Oceanography, vol. 27, no. 2, pp. 201-211, 1982.

[7] P. Minnett and A. Kaiser-Weiss, "Near-surface oceanic temperature gradients. Group for high resolution sea-surface temperature (GHRSST) discussion document, p. 7, 2012," https://www .ghrsst.org/files/download.php? $\mathrm{m}=$ documents\&amp; $\mathrm{f}=1201131$ 21306-SSTDefinitionsDiscussion.pdf.

[8] G. Stanhill, "Changes in the surface temperature of the dead sea and its heat storage," International Journal of Climatology, vol. 10, no. 5, pp. 519-536, 1990.

[9] R. Nehorai, N. Lensky, S. Brenner, and I. Lensky, "The dynamics of the skin temperature of the dead sea," Advances in Meteorology, vol. 2013, Article ID 296714, 9 pages, 2013.

[10] R. Nehorai, I. M. Lensky, N. G. Lensky, and S. Shiff, "Remote sensing of the Dead Sea surface temperature," Journal of Geophysical Research: Oceans, vol. 114, no. 5, Article ID C05021, 2009.

[11] I. Steinhorn, "In situ salt precipitation at the Dead Sea," Limnology and Oceanography, vol. 28, no. 3, pp. 580-583, 1983.

[12] I. Gertman, N. Kress, B. Katsenelson, and P. Zavialov, "Equations of state for the Dead Sea and Aral Sea: searching for common approaches," Final report of Russian-Israel cooperation project 3-3575, 2010.

[13] N. G. Lensky, A. Arnon, and I. Sirota, Halite precipitation rates in the Dead Sea: seasonal and spatial variations and their limnological and geological implications. Geophysical Research Abstracts. 17, EGU2015-11848, 2015. 
[14] A. Arnon, J. S. Selker, and N. G. Lensky, "Thermohaline stratification and double diffusion diapycnal fluxes in the hypersaline Dead Sea," Limnology and Oceanography, vol. 61, no. 4, pp. 12141231, 2016.

[15] P. Kishcha, D. Rieger, J. Metzger et al., "Modelling of a strong dust event in the complex terrain of the Dead Sea valley during the passage of a gust front," Tellus B: Chemical and Physical Meteorology, vol. 68, no. 1, Article ID 29751, 2016.

[16] P. Kishcha, B. Starobinets, A. Savir, P. Alpert, and M. Kaplan, "Foehn-induced effects on dust pollution, frontal clouds and solar radiation in the Dead Sea valley," Meteorology and Atmospheric Physics, pp. 1-15, 2017.

[17] W. G. Spangenberg and W. R. Rowland, "Convective circulation in water induced by evaporative cooling," Physics of Fluids, vol. 4, no. 6, pp. 743-750, 1961.

[18] T. D. Foster, "Onset of convection in a layer of fluid cooled from above," Physics of Fluids, vol. 8, no. 10, pp. 1770-1774, 1965.

[19] I. Steinhorn, "On the concept of evaporation from fresh and saline water bodies," Water Resources Research, vol. 27, no. 4, pp. 645-648, 1991.

[20] M. E. Stern, "The "salt-fountain" and thermohaline convection," Tellus, vol. 12, no. 2, pp. 172-175, 1960.

[21] P. Kishcha, B. Starobinets, I. Gertman, T. Ozer, and P. Alpert, "Unexpected pronounced heating in the uppermost layer of the Dead Sea after a sharp drop in noon surface solar radiation," Geophysical Research Abstracts, vol. 18, Article ID EGU20161807, 2016. 

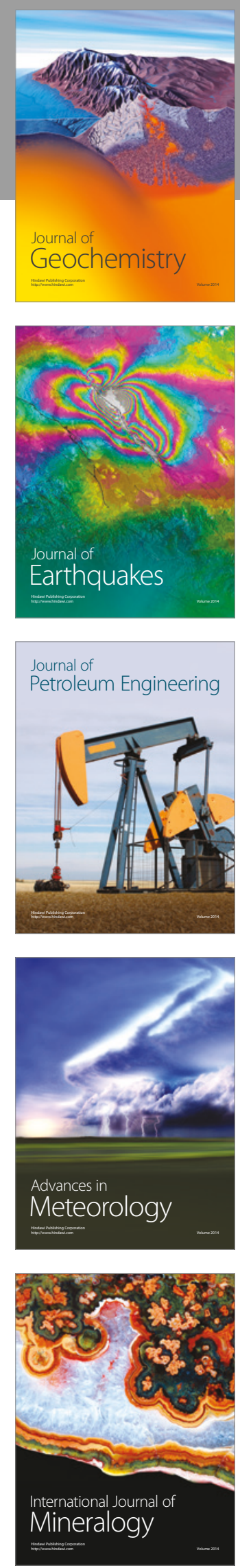
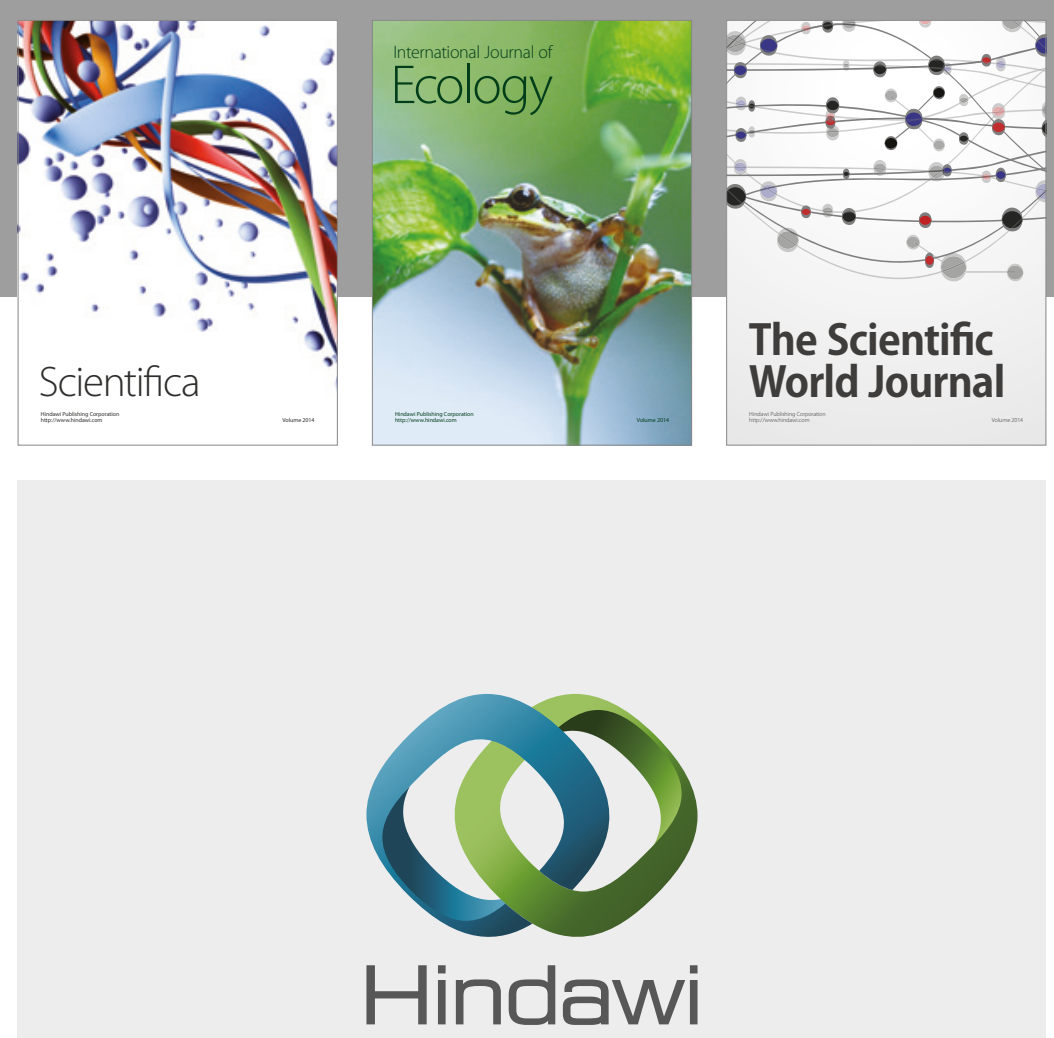

Submit your manuscripts at

https://www.hindawi.com
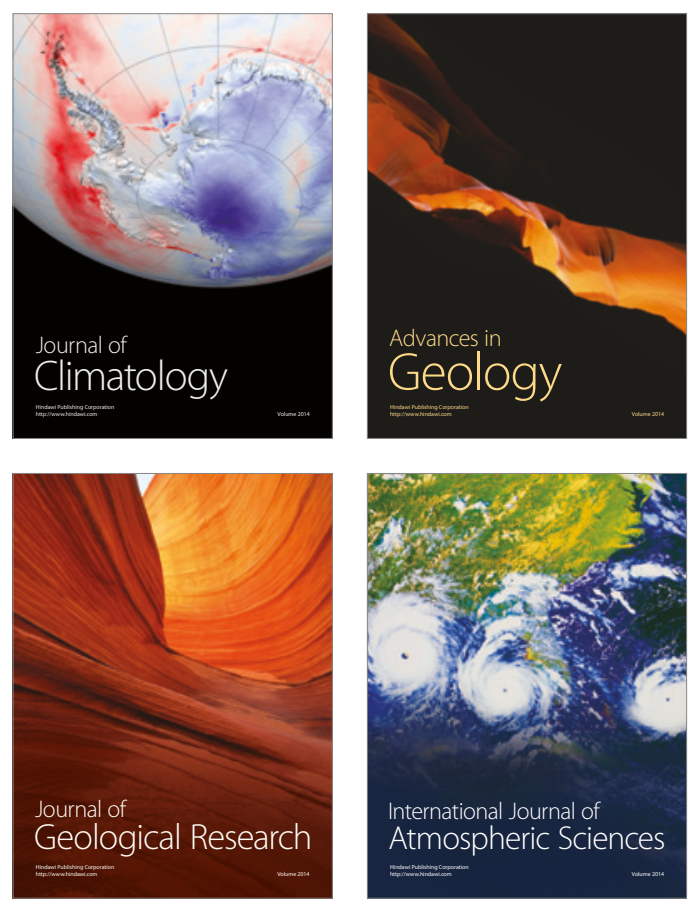

The Scientific

World Journal
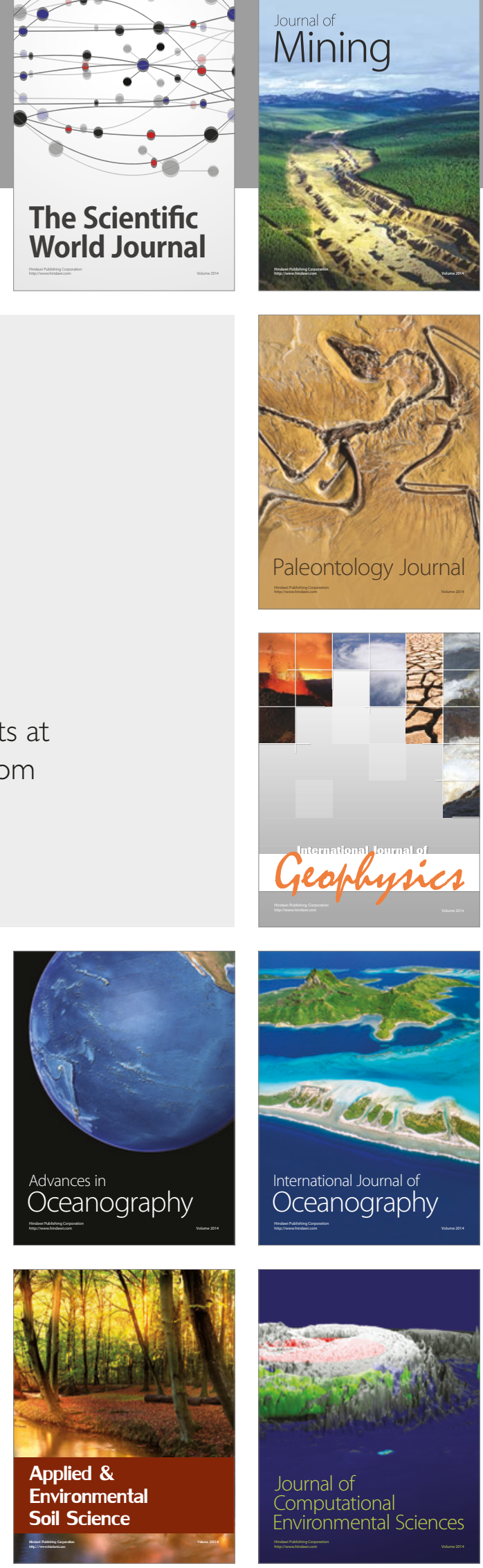